\title{
Burnout in pediatric critical care medicine: more challenging days during the COVID-19 pandemic
}

\author{
(iD) Isadora Souza Rodriguez ${ }^{1}$ \\ Pollyana Coelho Pessoa Santos ${ }^{1}$ \\ (iD)Artur Figueiredo Delgado ${ }^{1}$ \\ (iD) Werther Brunow de Carvalho'
}

1. Instituto da Criança e do Adolescente (ICr), Hospital das Clinicas HCFMUSP, Faculdade de Medicina, Universidade de São Paulo, SP, Brasil.

KEYWORDS: Coronavirus Infections. Pandemics. Critical Care. Burnout, Professional. Estresse Psicológico. Intensive Care Units, Pediatric.

\section{INTRODUCTION}

Physicians have more night shifts and consecutive workdays in COVID-19 times'. Burnout syndrome is a global burden experienced in pediatric critical care medicine (PCCM) as well as other specialties and by professionals in the healthcare practice. Despite the lack of robust evidence in this topic, the medical literature has shown a prevalence of $40-70 \%$ of this condition among critical care physicians. Along with its social burden, burnout also has a negative relationship with individual clinician productivity that can impact in patient safety, as it can be associated with higher error rates and lower patient satisfaction ${ }^{2,3}$. Burnout, depression, and other mental health problems such as anxiety and stress are highly correlated, and severe/extreme cases have been described in up to $20 \%$ of residents in a Brazilian study performed in our university ${ }^{4}$.

Among physicians, PCCM fellows need to be under surveillance for signs of burnout. This syndrome is characterized by impairment in personal and professional achievement, depersonalization, and emotional exhaustion. Suttle et al. ${ }^{1}$ described risk factors such as: lower satisfaction with PCCM, educational debits, second year of training, lower comfort level of seeking co-fellow and faculty help. Resident physicians and fellows are young doctors, in general, and satisfaction with the career choice in pediatric critical care and comfort discussing patient care or educational topics are essential for personal accomplishment. Other factors such as spirituality and having a stress outlet can be useful, as emphasized by the mentioned study ${ }^{1}$.

It is interesting to notice that even in different hospitals, there seems to be a similar pattern of behavior regarding burnout, indicating that this is a national - even global - problem, and can be identified among residents during the pediatric intensive care unit (PICU) routine ${ }^{1,5,6}$. The potential differences between countries are associated with individual experiences during fellowship programs, and in overwhelming periods some resident physicians or fellows are at high risk of moral distress and other situations that predispose burnout. In Brasil, for example, the first year of the program is considered the most stressful because many students have to move to another city 
or even state. Leaving home is an additional challenge such as initiating a new fellowship program and adapting to a different hospital. Besides this, all fellows bear the responsibility of caring for critically ill children, participating in decision-making processes, and discussing complex cases with faculty.

In the last few months, the novel coronavirus disease of 2019 (COVID-19) pandemic has resulted in a real cascade of new cases of depression and anxiety, and an exacerbation of existing mental health issues ${ }^{6}$. When experiencing burnout symptoms, health care professionals may develop a sense of detachment from work, both physically and psychologically ${ }^{7}$. During this pandemic, an emergency situation filled with unpredictability, some elements based on autonomy, competency, and relatedness should be restored ${ }^{6,7}$.

Burnout should be an institutional concern and all fellowship programs must stimulate adequate preventive measures, mainly family support, hobbies, solitude/company ${ }^{8}$. It's very important to promote maximum well-being for all healthcare professionals, but at the same time, it is not easy to establish mechanisms and strategies within our intensive care units to attempt to put well-being concepts into practice. All of us should have well-being initiatives to impact health professionals and patients. Several successful approaches have been carried out, such as comfortable and safe space for the entire team, supporting coffee breaks, promoting good mental health (reinforcing the positive), maintaining pride in being an intensivist, promoting safe virtual forums to discuss anxiety and concerns of the entire team with the psychology staff ${ }^{6,9}$.

The use of questionnaires with simple tools such as Google Forms was adopted in our hospital. We think that this instrument can help all PICU to perform a rapid evaluation of stress and anxiety levels. This assessment can be useful for acute initiatives to implement postures that promote well-being.

We reckon that clinician productivity could be improved with psychological support, avoiding moral distress and burnout in common or pandemic days. We have to care for those who are caring for our patients.

PALAVRAS-CHAVE: Infecções por Coronavirus. Pandemias. Cuidados Críticos. Esgotamento Profissional. Stress, Psychological. Unidades de Terapia Intensiva Pediátrica.

\section{REFERENCES}

1. Suttle ML, Chase MA, Sasser WC $3^{\text {rd }}$, Moore-Clingenpeel M, Maa T, Werner A, et al; Education in Pediatric Intensive Care (E.P.I.C.) Investigators. Burnout in Pediatric Critical Care Medicine Fellows. Crit Care Med. 2020;48(6):872-80.

2. Odonkor ST, Frimpong K. Burnout among healthcare professionals in Ghana: a critical assessment. Biomed Res Int. 2020;2020:1614968.

3. Kerlin MP, McPeake J, Mikkelsen ME. Burnout and joy in the profession of Critical Care Medicine. Crit Care. 2020;24(1):98.

4. Pasqualucci PL, Damaso LLM, Danila AH, Fatori D, Lotufo Neto F, Koch VHK. Prevalence and correlates of depression, anxiety, and stress in medical residents of a Brazilian Academic Health System. BMC Med Educ. 2019;19(1):193.

5. Wolfe KK, Unti SM. Critical care rotation impact on pediatric resident mental health and burnout. BMC Med Educ. 2017;17(1):181.
6. Larson CP, Dryden-Palmer KD, Gibbons C, Parshuram CS. Moral distress in PICU and neonatal ICU practitioners: a cross-sectional evaluation. Pediatr Crit Care Med. 2017;18(8):e318-26.

7. Hartzband P, Groopman J. Physician burnout, interrupted. N Engl J Med. 2020. doi: 10.1056/NEJMp2003149

8. Koval KW, Lindquist B, Gennosa C, Mahadevan A, Niknam K, Patil S, et al. First look at emergency medical technician wellness in India: application of the Maslach Burnout Inventory in an unstudied population. PLoS One. 2020;15(3):e0229954.

9. Donnelly PD, Davidson M, Dunlop N, MacGale M, Milligan E, Worral M, et al. Well-being during coronavirus disease 2019: a PICU practical perspective. Pediatr Crit Care Med. 2020. doi: 10.1097/PCC.0000000000002434. 